Pteridines

Vol. 6, 1995, pp. 69-73

\title{
Effect of Sepiapterin, 7,8-Dihydrobiopterin, 5,6,7,8-Tetrahydrobiopterin and Xanthopterin on Cholesterol and Phospholipid Content and Phos- pholipid Biosynthesis in vitro
}

\author{
Vera Rudzite, Edite Jurika, Gabriele Baier-Bitterlich,\# Helmut Wachter, Dietmar Fuchs ${ }^{\#}$ \\ Latvia Institute of Cardiology, Riga, Latvia \\ "Institute of Medical Chemistry and Biochemistry, University of Innsbruck, Innsbruck, Austria
}

(Received April 10, 1995)

\begin{abstract}
Summary

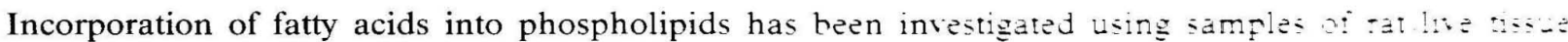
homogenate, Krebs-Ringer-phosphate buffer $(\mathrm{pH}=7.4)$ containing $0.3 \circ_{0}$ albumin. fatty acid mix:ure $2=\dot{0}$ glycerol. The addition of sepiapterin, 7,8-dihydrobiopterin and 5.6.7.8-tetrahydrobiopterin 15 and $30 \mathrm{Fmol} \equiv$ wet weight) to incubation medium induced a decrease of saturated (stearic acid) and an increase of polyunsaturated (arachidonic acid) fatty acids incorporation into phospholipids. Cholesterol content decreased, but phospholiplid content did not change in samples containing sepiapterin, 7,8-dihydrobiopterin and 5,6,7,8-tetrahydrobiopterin. No changes of fatty acid incorporation into phospholipids as well as of the content of cholesterol and phospholipids were observed in samples after the addition of xanthopterin ( 4 and $20 \mathrm{nmol} / \mathrm{g}$ wet weight) to incubation medium for phospholipid biosynthesis in vitro. The observations made by incubation with 7,8-dihydrobiopterin, 5,6,7,8-tetrahydrobiopterin and sepiapterin where in opposite to those made earlier employing neopterin and using the same incubation procedure.
\end{abstract}

Key Words : sepiapterin, 7,8-dihydrobiopterin, 5,6,7,8-tetrahydrobiopterin, xanthopterin, fatty acids, phospholipids, cholesterol

\section{Introduction}

Activation of the immune system is followed by the release of specific cytokines such as interferon- $\gamma$ and tumor necrosis factor- $\alpha(1)$ as well as an increase of kynurenine, neopterin and 5,6,7,8-tetrahydrobiopterin biosynthesis $(2,3)$. It is also found that some types of cellular regulation are associated with changes in membrane fluidity. For example, neoplastic transformation of cells is known to be accompanied by a marked increase in cell surface fluidity. Both, cell cycle regulation and contact inhibition of cells are also known to be linked with membrane fluidity

$\S$ Author to whom correspondence should be addressed. changes. These changes have been demonstrated to be a function of the membrane cholesterol/phospholipid ratio so that a relatively low ratio is associated with increased fluidity (4), and it also depends on cholesterol content in samples as well as fatty acid composition of phospholipids (5). An increase of cholesterol content in membranes and a decrease of polyunsaturated fatty acid content of membrane phospholipids have been observed in patients with arterial hypertension, myocardial infarction as well as at aging (6-9). Moreover, diseases as arterial hypertension (10-11), cardiomyopathy (12-15), atherosclerosis $(16,17)$ as well as aging $(18)$ are accompanied with elevated kynurenine and neopterin levels in blood serum. 
Our previous studies have demonstrated that the addition of kynurenine and neopterin to rat homogenized liver samples for phospholipid biosynthesis in vitro is followed by a decrease of polyunsaturated fatty acid incorporation into phospholipids as well as an increase of cholesterol content in samples $(19,20)$. The purpose of this study was to continue these investigations by the examination of the effets of sepiapterin, 7,8-dihydrobiopterin, 5,6,7,8-tetrahydrobiopterin and xanthopterin on phospholipid biosynthesis in vitro.

\section{Methods}

Homogenized liver tissue of 16 male Wistar rats in Krebs-Ringer-phosphate buffer $(\mathrm{pH}=7.4)$ containing $0.3 \%$ albumin were used for these experiments (19-21). Samples were incubated at $37^{\circ} \mathrm{C}$ two times for 4 hours. To investigate the effect of different pteridines, sepiapterin $(5$ and $30 \mathrm{pmol} / \mathrm{g}$ wet weight), 7,8-dihydrobiopterin ( 5 and $30 \mathrm{pmol} / \mathrm{g}$ wet weight), 5,6,7,8-tetrahydrobiopterin (5 and $30 \mathrm{pmol} / \mathrm{g}$ wet weight) and xanthopterin (4 and $20 \mathrm{nmol} / \mathrm{g}$ wet weight) were added to experimental test tubes before the first incubation. All pteridine derivatives were obtained from Schircks Laboratories, Jona, Switzerland. All the metabolites were diluted with bidistilled water. The same volume of bidistilled water $(0.1 \mathrm{ml})$ without addition of metabolites was added to the control test tubes. After the incubation at $37^{\circ} \mathrm{C}$ for 4 hours $60 \mu \mathrm{l}$ of $20 \%$ fatty acid solution in chloroform (stearic, palmitic, linoleic, oleic and arachidonic acid in equivalent amounts, Sigma, $\mathrm{Mu}-$ nich, Germany) and $40 \mu \mathrm{l}$ of glycerol were added to all test tubes. Then the test tubes were again incubated at $37^{\circ} \mathrm{C}$ for 4 hours. After this second incubation $75 \mathrm{ml}$ of choroform/methanol mixture (2: 1) was added to each sample. The samples were mixed and left for $40 \mathrm{~min}$ at room temperature. Then the chloroform/methanol extract was filtered and the filtrate was carefully treated according to the method of Folch et al.(22). The whole cholesterol concentration was determined by the method of Engelhard and Smirnova (23), the amount of phospholipids by the method of Urbach-Raabe (24). The method of Kates (25) was used to prepare the phospholipid samples for fatty acid examination by gas chromatography. Helium was used as a carrier gas and the sorbent was chromosorb covered with DEAG. Separated fatty acid methylesters were monitored at $210^{\circ} \mathrm{C}$, using flame ionization detection and an adequate flow rate of helium.

The separation was controlled by internal methylester standard substances (Serva).
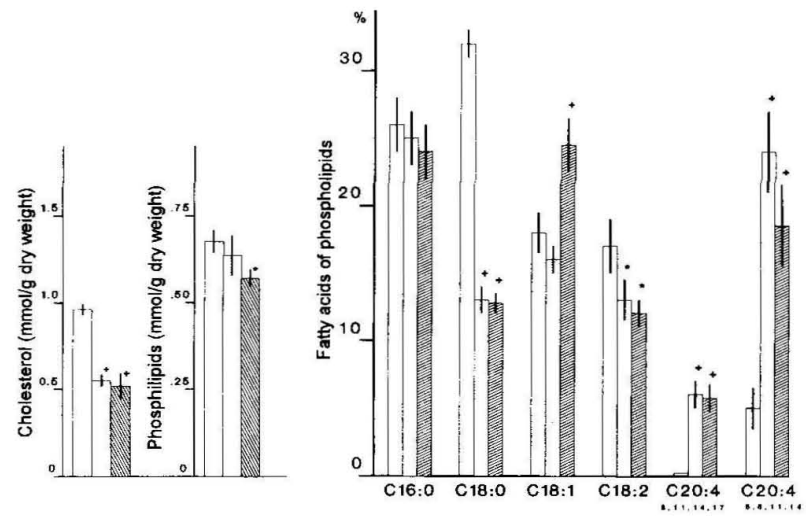

Figure 1. Concentrations (mean \pm S.D.) of cholesterol and phospholipids, as well as fatty acid content (in percent: mean \pm S.D.) of phospholipids in controls (open bars) and in samples with $5 \mathrm{pmol} / \mathrm{g}$ wet weight (dotted bars) or with 30 $\mathrm{pmol} / \mathrm{g}$ wet weight (hatched bars) sepiapterin. Samples of rat liver tissue homogenates were used to test for phospholipid biosynthesis in vitro. Incubation medium: Krebs-Ringer-phosphate buffer $(\mathrm{pH}=7.4)$, fatty acid mixture and glycerol. Samples were incubated twice for $4 \mathrm{~h}$ at $37^{\circ} \mathrm{C}$.

${ }^{*}$ The changes are statistically significant $(\mathrm{p}<0.05)$.

${ }^{\dagger}$ The changes are statistically significant $(\mathrm{P}<0.001)$.

Statistical analyses were dong using Student's ttest. P-values below 0.05 were considered to indicate significant differences (26).

\section{Results}

Fig. 1 shows the changes of phospholipid biosynthesis after addition of sepiapterin (5-30 pmol/g wet weight) to samples. We observed a decrease of stearic acid $(\mathrm{p}<0.05)$ and an increase of arachidonic acid $(\mathrm{p}<0.001)$ incorporation into phospholipids. Chromatograms of experimental samples showed the appearance of 5,8,11,14-arachidonic acid as well as 8,11,14,17-arachidonic acid, while control samples contained only 5,8,11,14-arachidonic acid. Addition of sepiapterin did not change the phospholipid content in samples, while cholesterol content significantly decreased $(\mathrm{p}<0.001)$.

Fig. 2 Points out the deviation of phospholipid biosynthesis after the addition of 7,8-dihydrobiopterin to the incubation medium. We observed the same changes as in the cases with sepiapterin: a decrease of stearic acid $(\mathrm{P}<0.001)$ and an increase of two types of arachidonic acid $(8,11,14,17$-arachidonic acid: $\mathrm{P}<0.001$ and 5,8,11,14-arachidonic acid; $\mathrm{p}<0.001$ ) content of phospholipids. The cholesterol content in samples containing 7,8-dihydrobiopterin decreased $(\mathrm{P}<0.001)$ but the amount of phospholipid remained unchanged.

Fig. 3 shows the changes of phospholipid biosynthesis after addition of 5,6,7,8-tetrahydrobiopterin ( 5 

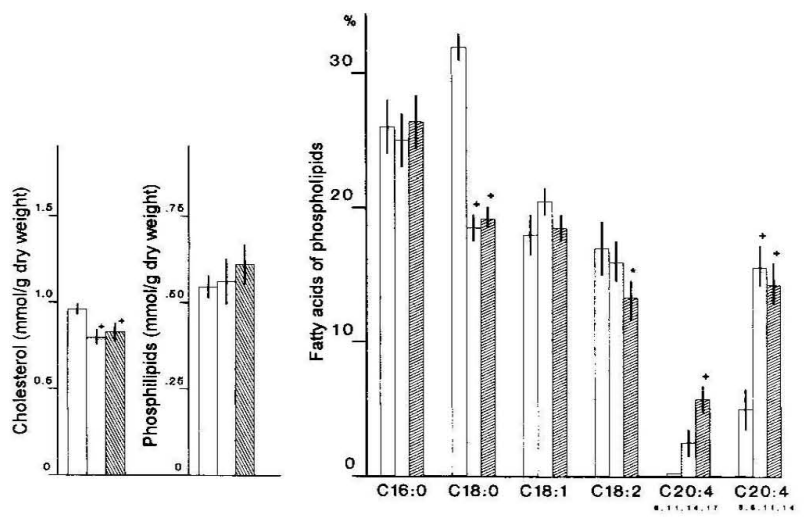

Figure 2. Concentrations (mean \pm S.D.) of cholesterol and phospholipids, as well as fatty acid content (in percent: mean \pm S.D.) of phospholipids in controls (open bars) and in samples with $5 \mathrm{pmol} / \mathrm{g}$ wet weight (dotted bars) or with $30 \mathrm{pmol} / \mathrm{g}$ wet weight (hatched bars) 7,8-dihydrobiopterin. Samples of rat liver tissue homogenate were used to test for phospholipid biosynthesis in vitro. Incubation medium: krebs-Ringer-phosphate buffer $(\mathrm{pH}=7.4)$, fatty acid mixture and glycerol. Samples were incubated twice for $4 \mathrm{~h}$ at $37^{\circ} \mathrm{C}$. *The changes are statistically significant $(p<0.05)$.

${ }^{\dagger}$ The changes are statistically significant $(\mathrm{p}<0.001)$.
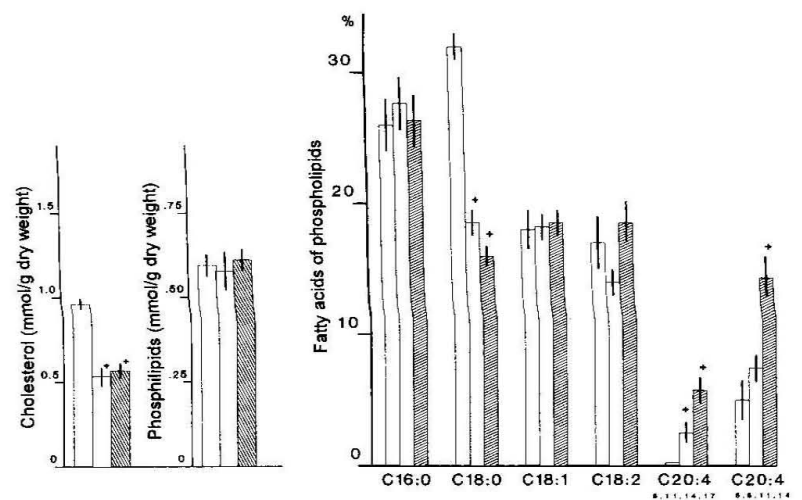

Figure 3. Concentrations (mean \pm S.D.) of cholesterol and phospholipids, as well as fatty acid content (in percent: mean \pm S.D.) of phospholipids in controls (open bars) and in samples with $5 \mathrm{pmol} / \mathrm{g}$ wet weight (dotted bars) or with 30 $\mathrm{pmol} / \mathrm{g}$ wet weight (hatched bars) 5,6,7,8-tetrahydrobiopterin. Samples of rat liver tissue homogenate were used to test for phospholipid biosynthesis in vitro. Incubation medium: Krebs-Ringer-phosphate buffer $(\mathrm{pH}=7.4)$, fatty acid mixture and glycerol. Samples were incubated twice for $4 \mathrm{~h}$ at $37^{\circ} \mathrm{C}$. ${ }^{\dagger}$ The changes are statistically significant $(p<0.001)$.

and $30 \mathrm{pmol} / \mathrm{g}$ wet weight) to samples. We have observed the same changes as in the case with sepiapterin and with 7,8-dihydrobiopterin: a decrease of stearic acid $(\mathrm{p}<0.05)$ and an increase of two types of $8,11,14,17$-arachidonic acid $(\mathrm{p}<0.001)$ and of $5,8,11,14$-arachidonic acid $(\mathrm{P}<0.001)$ incorporation into phospholipids. The amount of cholesterol decreased in samples, but the content of phospholi-
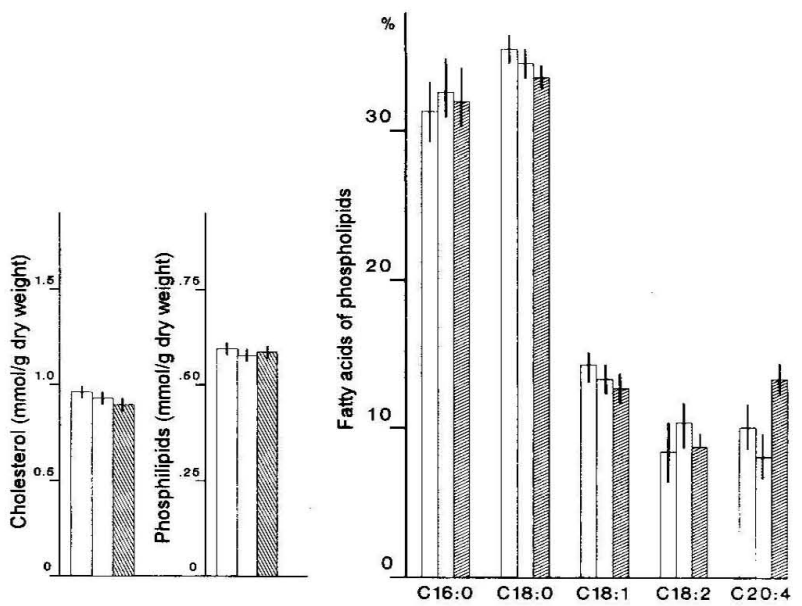

Figure 4. Concentration (mean \pm S.D.) of cholesterol and phospholipids, as well as fatty acid content (in percent: mean \pm S.D.) of cholesterol and phospholipids, as well as fatty acid content (in percent: mean \pm S.D.) of phospholipids in controls (open bars) and in samples with $5 \mathrm{pmol} / \mathrm{g}$ wet weight (dotted bars) or with $30 \mathrm{pmol} / \mathrm{g}$ wet weight (hatched bars) xanthopterin. Samples of rat liver tissue homogenate were used to test for phospholipid biosynthesis in vitro. Incubation medium: Krebs-Ringer-phosphate buffer $(\mathrm{pH}=7$. 4), fatty acid mixture and glycerol. Samples were incubated twice for $4 \mathrm{~h}$ at $37^{\circ} \mathrm{C}$

pids was not altered.

Fig. 4 reflects the influence of xanthopterin (4 and $20 \mathrm{nmol} / \mathrm{g}$ wet wight) on phospholipid biosynthesis in vitro. Addition of xanthopterin to samples for phospholipid biosynthesis in vitro did neither alter incorporation of fatty acids into phospholipids, nor the content of cholesterol and phospholipid.

\section{Discussion}

We have observed a decreased incorporation of saturated fatty acid (stearic acid) and an increase of polyunsaturated fatty acid (arachidonic acid) incorporation into phospholipids 4 hours after the addition of either sepiapterin, 7,8-dihydrobiopterin or 5,6,7,8-tetrahydrobiopterin to the incubation medium for phosholipid biosynthesis in vitro. These deviations of fatty acid incorporation were followed by a decrease of cholesterol but the content of phospholipids did not change in samples. Literature studies show that cell stimulation as well as neoplastic transformation is accompanied by de novo synthesis of phospholipids which is increased not earlier than 6 hours after the stimulation. However the increased incorporation of unsaturated fatty acids was found within the first hours of stimulation (5). Therefore the results received in our present experiments allow us to suggest that 5,6,7,8-tetra- 
hydrobiopterin and related compounds like reduced pterin-species, sepiapterin and 7,8-dihydropterin, take part in the stimulation of cell cycle by changing cholesterol/phospholipid ratio and increasing the incorporation of polyunsaturated fatty acids (arachidonic acid especially) into phospholipids.

When comparing the results obtained from this study with our data obtained earlier using neopterin and kynurenine in the same assay system it is exciting to see the inverse relationship between the effects induced by the reduced biopterin derivatives including sepiapterin in relation to neopterin. Whereas 7,8-dihydrobiopterin, 5,6,7,8-tetrahydrobiopterin and sepiapterin supported incorporation of polyunsaturated fatty acids into phospholipids but decreased cholesterol formation, neopterin did the opposite $(19,20)$. From the data it appears that neopterin may interfere with some positive effects which the reduced biopterin derivatives may have on lipid metabolism. The enhanced formation of neopterin during immunopathologies may be involved to induce a shift towards a decrease of polyunsaturated fatty acid content of membrane phospholipids and increase cholesterol content, thus enhancing the risk of, e. g. atherosclerosis and myocardial infarction. Neopterin appears to be the "bad guy" interfering with the protective effects achieved by 7,8-dihydro-biopterin, 5,6,7,8-tetrahydrobiopterin and sepiapterin.

Recently, pteridine derivatives have been shown to be able to interfere with radical-mediated chemical reactions $(27,28)$. Naturally occuring, fullyoxidized pterin derivatives tend to have a promoting effect on such reactions whereas reduced pterin species tend to react as scavengers. It would be interesting to know whether this behaviour of pterins is important to explain our findings. Further studies are needed to test for eventual divergent effects of 7,8-dihydroneopterin and biopterin on cholesterol and phospholipid biosynthesis providing a clue whether the configuration of the pterin-(6)-side chain or the oxidation state of the peridines is more important for the effects seen.

\section{References}

1. Whicher. J.T., Evens S.W. Cytokines in disease. Clin. Chem., 1990, 36, 1269-1281.

2. Fuchs D., Hausen A. Reibnegger G., Werner E.R., Dierich M.P., Wachter H. Neopterin as a marker for activated cell-mediated immunity:Application in HIV infection. Immunol. Today, 1988, 9, 150-155.

3. Wachter H., Fuchs D., Hausen A., Reibnegger G., Weiss G., Werner E.R., Werner-Felmayer G. Neopterin: Biochemistry-Methods-Clinical Application. Walter de
Gruyter, Berlin-New York, 1992.

4. Ostro M.J., Bessinger b., Summers J., Dray S. Effect of membrane lipid composition on mobility of lymphocyte surface immunoglobulins. In: Membrane Fluidity. Biochemical Techniques and Cellular Regulation. M. Kates and A. Kuksis Eds. The Humana Press Inc. Clifton, New Jersey, 1980, p. 105-117.

5. Ferber E., Kroner E., Schmidt B., Ficher H., Peskar B.A., Anders C. Dynamics of membrane fatty acid during lymphocyte stimulation by mitogens. In: Membrane Fluidity. Biophysical Techiniques and Cellular Regulation. M. Kates and A. Kuksis Eds. The Humana Press Inc. Clifton, New Jersey, 1980, p. 239-263.

6. Montilla C., Muniz O., Villar J., Ruiz-Gutierrez V., Serreras J. L. Erythrocyte membrane cholesterol and phospholipids composition in hypertensives vs normotensives. In: Abstracts of 1st International Congress "Fatty Acid and Lipids from Cell Biology to Human Disease" Lugano, Switzeland, 1993, p. 116.

7. Muniz O., Montilla C., Villar J., Ruiz-Guitierrez V., Stiefer P., Serreras J.L. Erythrocyte membrane fatty acids composition in hypertensives vs normotensives. Abstracts of 1st International Congress "Fatty Acids and Lipids From Cell Biology to Human Disease”. Lugano, Switzerland 1993, p. 116.

8. Cloete F., de Waal J.M., Badenhorst P. W. Kelderman M. Abnormal fatty acid composition of plasma and platelets in patients with acute myocardial infarction. In: Abstracts of 1st International Congress "Fatty Acids and Lipids from Cell Biology to Human Disease.” lugano, Switzerland. 1993, p. 109.

9. Olivieri O., Stanzial A.M., Trevisan M.T., Guarini P., Terzi M., Caffi S., Fontana F., Casaril M., Ferrari S., Corrocher R. Selenium status, fatty acids, antioxidant vitamins and aging. The none study. In: Abstract of 1st International Congress "Fatty Acids and Lipids from Cell Biology to Human Disease” Lugano, Switzerland, 1993, p. 136.

10. Rudzite V., Jurika E., Arajs J., Andrejev N. The relationship between kynurenine and arterial blood pressure. In: Progress in Tryptophan and Serotonin Research 1986. Bender D.A., Joseph M.H., Kochen W., Steinhart H. Eds. Walter de Gruyter \& Co, Berlin-New York 1987, 127-130.

11. Rudzite V., Sileniece G., Liepina D., Dalmane A. 1mpairment of kynurenine metabolism in cardiovascular disease. Adv. Exp. Med. Biol., 1991, 294, 663-667.

12. Rudzite V., Sileniece G., Jirgensons J., Dalmane A., Zirne R., Jurika E., Skards J.I. The significance of increased kynurenine levels in blood to the development of cardiovascular pathology. Acta Medica Baltica, 1994 1, 4-19.

13. Rudzite V., Skards J.I., Fuchs D., Reibnegger G., Wachter H. Serum kynurenine and neopterin concentrations in patients with cardiomyopathy. Immunol. Lett., 1992, 32, 125-130.

14. Samsonov M., Fuchs D., Reibnegger G., Belenkov J.N., Nassonov E.L., Wachter H. Patterns of serological markers for cellular immune activation in patients with dilated cardiomyophathy and chronic myocarditis. Clin. Chem.. 1992, 38, 678-680.

15. Fuchs D., Samsonov M., Tilz G.P., Reibnegger G., Be- 
lenkov J.N., Nassonov E.L., Wachter H. Stimulated cellular immune system in patients with congestive heart failure. Eur. J. Clim. Clin. Biochem., 1993, 31, 111-114.

16. Tatzber F., Rabl H., Koriska K., Erhart U., Puhl H., Waeg G., Krebs A., Esterbauer H. Elevated serum neopterin levels in atherosclerosis. Atherosclerosis, 1991, 89, 203208.

17. Weiss G., Willeit E., Kiechl S., Fuchs D., Jarosch E., Oberhollenzer F., Reibnegger G., Tilz G.P., Gerstenbrand F.m Wachter H. Increased concentrations of neopterin in carotid atherosclerosis. Atherosclerosis, 1994, 106, 263-171.

18. Reibnegger G., Huber L.A., Jürgens G., Schönitzer D., Werner E.R., Wachter H., Wick G., Traill K. N. Approach to define "normal aging" in man. Immune function, serum lipids, lipoproteins and neopterin levels. Mech. Ageing Developm., 1988, 46, 67-82.

19. Rudzite V., Jurika E., Reibnegger G., Wachter H., Fuchs D. Influence of kynurenine, neopterin. noradrenaline and pyridoxal-5-phosphate on cholesterol and phospholipid content and phospholipid biosynthesis in vitro. Pteridines, 1993, 4, 126-130.

20. Rudzite V., Jurika E., Fuchs D., Reibnegger G.. Wachter $H$. The influence of kynurenine, neopterin and pyridoxal-5-phosphate/P-5-P/ on cholesterol content and phospholipid biosynthesis in vitro. In: L-Tryptophan Current Prospects in Medicine and Drung Safety, Kochen W. and Steinhart H. Eds. Walter de Gruyter, Berlin-New
York, 1994, 165-170.

21. Nilsson S. Synthesis and secretion of biliary phospholipids in man. Acta Chirurg. Scand. 1870, Suppl. 405, 1-38.

22. Folch J., Lees M., Stanley G.H.A Simple method for isolation and purification of total lipids from animal tissues. J. Biol. Chem., 1957, 226, 495-509.

23. Preditetchenski V.J., Borovskaja V.M., Margolina L.T. Handbook of Clinical and Laboratory Investigation, Medgiz, Moscow, 1950 (Russ.)

24. Homolka J. Bestimmung des anorganischen Phosphors nach Urbach-Raabe (modifiziert). In: Chemische Diagnostikim Kindersalter mit Bevorzugung der Mikrometrischen Blutanalysen. VEB, Verlag Volk und Gesundheit, Berlin, 1964, 354-355.

25. Kates M. Technique of Lipidology. Mir, Moscow, 1978, 201-203 (Russ.).

26. Weber E. Grundriss der biologischen Statistik für Naturwissenschaftler, Landwirte und Mediziner. Gustav Fischer Verlag, Jena, 1957.

27. Weiss G.. Fuchs D.. Hausen A.. Reibnegger G.. Werner E.R.. Werner-Felmayer G.. Semenitz E.. Dierich. Neopterin modulates toxicity mediated by reactive oxyger ar. chloride species. FEBS Lett.. 199: : 1 1, s4-9:

28. Reibnegger G.. Fuchs D.. Murr C.. Dierich M.P. Prie1derer W.. Wachter $H$. Effects of pteridines on luminoldependent chemiluminescence induced by chloramineT. Free Radical Biol. Med. 1995: 18:515-523. 